\title{
FORUM
}

\section{THE ROLE OF STATE AND NON-STATE ACTORS IN THE SUSTENANCE OF THE EXPANDED PROGRAM ON IMMUNIZATION (EPI) IN LESOTHO, SOUTHERN AFRICA}

\author{
EMEKA E. OBIOHA-THOPE A. MATOBO ${ }^{I}$
}

\begin{abstract}
This study takes cognizance of the lingering crisis and politics in governing health sector system in sub-Saharan Africa. It articulates the role of the state and civil society groups in primary health provisioning and investigates the questions "how", "what", "why" and "who" that matter in Lesotho, where 83 percent of the population live in rural areas. The study utilized secondary clinical data at the national level as the basis for analysis which involved a lengthy desktop analysis of the Expanded Program on Immunization (EPI) clinic data and records. Data sources indicate that Lesotho's primary health care system is grassroot-oriented in implementation, with a very functional community health and voluntary health worker system. Close collaboration was also found to exist between the state organs and the Christian Health Association of Lesotho (CHAL) across the entire platform of health care delivery. The study identified the existence of some peculiar socio-environmental factors such as poor coordination, suspicion and communication gaps - among others - which are impeding the progress of the EPI in spite of the cordial relationship which exists between the state and other stakeholders/role-players.
\end{abstract}

KEYWORDS: Private, Partnership, Health Promotion, Africa, Leshoto

1 Emeka E. Obioha, (Corresponding author) Department of Social Sciences, Walter Sisulu University, Private Bag X1 Mthatha 5099, South Africa, Tel: +27790815604, E-mail: emekaobioha@gmail.com. Thope A. Matobo, Department of Sociology, Anthropology and Social Work, National University of Lesotho, PO Roma 180, Lesotho. E-mail: ta.matobo@, nul.ls 


\section{INTRODUCTION}

The primary health care sector in Lesotho could be described as a developing institution. It is presently in the form of a disorganized system that requires reorganization and revitalization. With particular reference to the Expanded Program on Immunization (EPI), the project has not achieved the much-expected goals of eradicating killer childhood diseases and other communicable diseases. Unarguably, immunization remains one of the most important and cost-effective strategies for the prevention and combating of childhood communicable diseases and is considered to be one of the cornerstones of primary health care (Government of Lesotho, 2001). Wittet and Aston, (2000) in their paper 'How Health Professionals Can Make the Difference' alluded to the fact that through childhood immunization three to four million young lives could be saved.

Discussing the socio-political environment, particularly the primary health sector in Lesotho, opens up a vista into an area of power relations in society. Analysis of the relative roles of the state and civil society groups and the relationship between the two in the implementation of the Expanded Program on Immunization (EPI) in Lesotho exposes the anatomy of the health crisis in the country about which lingering questions exist, concerning system access, equity and sustainability. Therefore, discussing the role of the state and civil society groups in primary health provisioning in Lesotho is important for understanding how, what, why and who matter in the country's health system. Obtaining deep knowledge and a proper grasp of the scenario could lead towards meaningful re-engineering of the entire health system for the benefit of the citizenry. Investigation of the issues of governance in Lesotho's health system is of great importance as the role of civil society groups and the private sector remains unspecified. Flowing from the above come the issues of participation, partnership and power relations between the major stakeholders in the primary health sector (the government and civil society) which deserve critical analysis for policy purposes. Against this background, this study will provide understanding of the primary health policy background as it relates to the EPI in Lesotho, as well as of the roles of state and non-state actors in the implementation of the program, the nature of the relationship/ partnership between the two entities (state and non-state) and the weaknesses of and challenges to the system. 


\section{RESEARCH ASSUMPTION AND QUESTIONS}

The main assumption of this study is that both state and non-state actors are working on an individual and collaborative basis in order to deliver quality, sustainable immunization of children in Lesotho, but the extent to which this goal is being realized needs to be investigated. From this primary assumption the following questions are raised:

- What specific roles do state and non-state agencies play in Lesotho's immunization program?

- Are there areas of overlap and cooperation?

- What is the nature of cooperation that exists between the two groups of entities (state and non-state)?

- What kinds of conflicts and challenges are manifested in the relationship between the role-players?

\section{LESOTHO'S EXPANDED PROGRAM ON IMMUNIZATION (LEPI): THE POLICY BACKGROUND}

According to UNICEF (2003), 'every government has a responsibility to create an environment where children's rights are protected and defended. Almost every country in the world has ratified the Convention on the Rights of the Child (CRC), which recognizes that children have the right to develop their fullest potential physically, mentally and socially, and to express their opinions freely. These rights should be guaranteed by the state'. The implementation of the EPI in Lesotho conforms with the Convention on the Rights of the Child and its success has always been an expectation of many Basotho.

In line with the above, the Ministry of Health and Social Welfare is further organized into social, curative and Primary Health Care (PHC) services. The $\mathrm{PHC}$ is arranged into various divisions and/or departments. For the purposes of this study we discuss the Family Health Division (FHD) which is the core of the Expanded Program on Immunization. On its establishment, the Family Health Division was tasked with the responsibility of improving the health and wellbeing of mothers and their children. The Programs under this division include Child Survival, Reproductive Health and Nutrition. The components of the Child Survival Program are as follows: The Expanded Program on Immunization (EPI), Acute Respiratory Tract Infection (ARI), Combating Childhood Diarrhea Diseases (CCDD) and The Child Nutrition and Household Food Security (CNHFS) Program. 
The main aim of EPI worldwide is to immunize children against communicable childhood diseases, thus preventing childhood morbidity and mortality. According to the Ministry of Health and Social Welfare (2001), UNICEF and the World Health Organization (2005) in their report which reviewed the EPI in Lesotho, immunization is regarded as the most costeffective primary health prevention intervention available to all nations, and EPI is regarded as the cornerstone of Primary Health Care worldwide. Through immunization, mothers and children can be saved from infection by six killer diseases. The World Health Organization's (1995) recommendations on the Expanded Program on Immunization indicated that all countries should immunize against polio, Diphtheria Pertussis and Tetanus Toxoid (DPT) and measles. However, countries with a high prevalence of tuberculosis (TB) infection should integrate immunization against TB and Hepatitis B into their routine immunization programs.

The Expanded Program on Immunization in Lesotho was established in 1979 and placed within the Family Health Division of the Ministry of Health and Social Welfare. It is further reported that, prior to the establishment of Lesotho's Expanded Program on Immunization (LEPI), immunization programs lacked intensity and managerial organization (UNICEF and WHO, 2005). The main focus of LEPI is to ensure that all children under five years old are fully immunized against the six killer communicable childhood diseases which are poliomyelitis, tuberculosis, measles, diphtheria, tetanus and whooping cough (Lesotho EPI, 2002). In response to the health challenges facing children in Lesotho, the Ministry of Health and Social Welfare, through Lesotho's Expanded Program on Immunization, decided to incorporate hepatitis B and haemophilias influenza into the immunization program during 2003-2005 (Ministry of Health and Social Welfare, Lesotho Expanded Program on Immunization, 2002).

With regard to the type of services, the main objective of Lesotho's Expanded Program on immunization "is to ensure that the immunization services offered in Lesotho are of high quality, acceptable, affordable and accessible to all mothers and children in Lesotho at all levels..." (pg.5) (this includes urban, remote and hard-to-reach rural places in Lesotho). The Ministry of Health and Social Welfare has established guidelines for LEPI policy implementation that are designed to serve as a reference for all health care providers with the view to improving the quality of immunization programs in Lesotho. The purpose of the guidelines is to interpret all policy statements in the EPI policy document and to describe the action which should be taken by all health providers and role players at various levels of care to effectively and successfully implement immunization programs. Fig. 
1 shows the guiding principles for the implementation of Lesotho's Expanded Program on Immunization.

\title{
Figure 1. Guiding Principles for EPI Implementation in Lesotho
}

\author{
1. Policy Statement on political Commitment \\ - The Government of Lesotho is committed to The Expanded Program on Immunization as a pillar for \\ child survival. This includes routine immunizations as well as disease elimination, eradication and \\ accelerated control initiatives. \\ - The Government is also committed to the program's sustainability. To ensure this, the policy advo- \\ cates for provision of adequate human, material and financial resources to provide immunization free \\ of charge to Lesotho's population.
}

2. Policy Statement on Community Participation and Social Mobilization (item 3.2):

- The MOHSW regards communities as the main stakeholder and partner in immunization programs, both routine EPI and National Immunization Days (NIDs)

- The MOHSW strategies will support all initiatives geared towards awareness creation, demands, attitude and community participation.

3. Policy Statement on Regulatory issues relating to immunization (item 3.3)

- The MOHSW will, within the framework of Health Reform program, update the Public Health Act to reflect modern thinking in regulating immunization activities. This will, among other things, cover the rights and responsibilities of individuals and communities as well as private sector towards vaccination.

4. Policy Statement on the integration of health Programs (Item 3.4)

- Immunization services will be provided as an integral part of the National Family Health program

- The EPI, known as one of the most cost-effective public health interventions, will be a part and parcel of the District Health Package (DHP) as a priority.

5. Policy Statement on Accessibility and Equity

- In order to achieve high immunization coverage among communities, the program will aim to be accessible to every child and women in childbearing age.

- To ensure equity and social justice the immunization will be provided to all target populations irrespective of ethnicity, political and religious affiliation

6. Policy statement on quality of Services and Safety of Immunizations (Item 3.6)

- One of the most important goals of the MOHSW is to improve the quality of health services provision including vaccinations.

- MOHSW will put under close surveillance the safety aspects of vaccination including health worker, vaccine handling and procedures of vaccinations.

7. Policy Statement on Coordination and Leadership (Item 3.7)

- MOHSW will show high leadership to rehabilitate the program through coordination and close monitoring.

- The coordination of the program will rest with the MOHSW through regular meetings and various committees with all partners

- The Minister of Health \& Social Welfare will chair the Interagency Coordinating Committee (ICC) as a forum for key stakeholders.

Source: Ministry of Health and Social Welfare (2002) Guidelines for LEPI policy implementation

The general policies on the Expanded Program on Immunization recommend that immunization services be provided at all health facilities and hospitals at all times, including on Saturday and Sunday (the so-called 'Supermarket Approach'). This is recommended with a view to reducing missed opportunities and ensuring that outreach services serve (i.e. immunize) 
all of the target population. The program supports the vaccination activities implemented by Health Service Areas (HSAs) through the procurement of vaccines, logistics and equipment such as syringes and needles. The program also conducts monitoring and supervision of HSA's immunization activities.

All Health Service Areas, including clinics, have to submit their monthly statistics to Lesotho's Expanded Program on Immunization. Similarly, the Health Centers and clinics have to submit their statistics through area hospitals (National EPI Review, Lesotho, July 2001). The program target groups are children under one year old and all childbearing women. The immunization schedule is depicted as follows in Table 1.

Table 1. Lesotho's Expanded Program of Immunization Schedule

\begin{tabular}{|l|l|}
\hline Time & Type of Vaccine \\
\hline At Birth & BCG, OPV0 \\
\hline At Six Weeks & DPT1, OPV1, HepB1, Hib 1 \\
\hline At 10 weeks & DPT2, OPV2, HepB2, Hib 2 \\
\hline At 14 weeks & DPT3, OPV3, HepB3, Hib3 \\
\hline At nine months & Measles \\
\hline Booster dose at 18 months & DPT and Measles \\
\hline
\end{tabular}

Source: Ministry of Health and Social Welfare (2002) Guidelines for LEPI policy implementation

\section{Lesotho's Expanded Program on Immunization (LEPI) Reporting System by Health Service Areas}

The Ministry of Health, Family Division has supplied Health Service Areas with tally sheets which are recorded and submitted to LEPI every month. In addition, immunization events (per child) are recorded in each client's personal record booklet, locally known as a "bukana." For the years under study, improvements in the recording system and the timely submission of LEPI data were observed, although reporting still remained below $90 \%$. The flow of information in the EPI program is depicted in Fig 2.

Private practitioners play an important role in immunization as some clients prefer to go to them for reasons of convenience. However, the flow of LEPI information does not show how information about immunization by private practitioners is collected or submitted to the LEPI office. This requires that a system should be put in place, to show how private practitioners ensure that their clients are fully immunized. The support, monitoring and evaluation 
of immunization activities undertaken by such practitioners should be the subject of a policy statement.

Figure 2. Information flow in the EPI Program

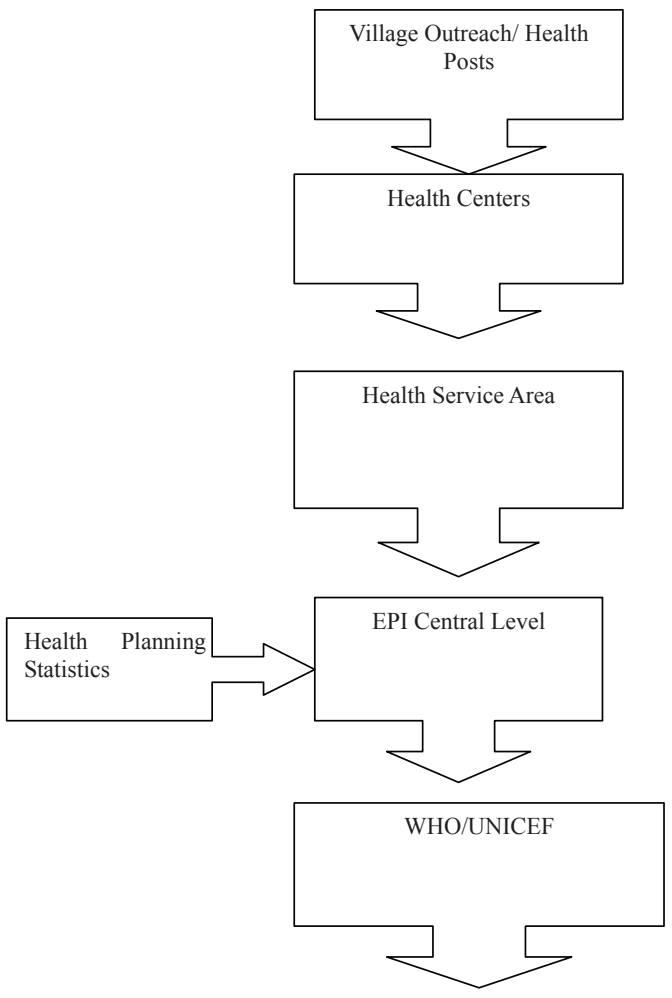

Source: PriceWaterHouseCooper, UNICEF, Global Alliance for Vaccine and Immunization and WHO, (2004)

\section{RESEARCH SETTING AND METHODOLOGY}

Lesotho is located in Southern Africa. It is an enclave within South Africa which is located at a latitude of $28^{\circ}, 35^{\prime} 40 \mathrm{~S}$ and longitude $27^{\circ} 00^{\prime}$ E. (South African Political Economy Series, 2001:7). With slightly over 2 million people, Lesotho's population is predominantly rural $(83 \%$ of the population). This study utilized secondary data at the national level as the 
basis for analysis and deductions. With regard to this, major sources include periodicals about immunization reports such as the World Bank Development Report, the Annual Statistical Report from Lesotho's Office of Statistics Maseru, and Health Policy documents from the Ministry of Health and Social Welfare. The study therefore involved a lengthy desktop analysis of The Expanded Program on Immunization clinic data and records made available by the Lesotho Extended Program on Immunization. Growth analysis was conducted on the data to obtain the percentage change output that was then used in the interpretation of the performance for the years studied.

\section{DESIGNATED ROLES OF STATE AND NON-STATE ACTORS IN THE IMPLEMENTATION OF THE EXPANDED PROGRAM ON MMUNIZATION IN LESOTHO}

In Lesotho, since its inception in 1979, EPI has received a lot of support from both the government and non-state actors. In spite of regime, change the program continuously receives considerable funding from the government budget despite the fact that budgetary allocations to the health sector are lower than those of other sectors (only 7\% of Government of Lesotho annual budget allocations were allocated to health). The Government of Lesotho, through the Ministry of Health and Social Welfare, has shown the requisite political will towards The Expanded Program on Immunization, its main objective being the routine immunization, eradication of polio and the elimination of measles and neonatal tetanus. Through the earmarked activities, the Ministry of Health and Social Welfare aims to reduce the infant mortality and morbidity that may be attributed to childhood communicable diseases.

An important and unique dimension of the government partnership is the existence of voluntary partners. The government of Lesotho has raised a substantial number of community health workers (typically village health workers and traditional birth attendants) who are mainly voluntary, officially unpaid individuals who have been given basic training in matters of health care and education. Village health workers, among other functions, play a preventative role in their communities, especially in rural locations. The relevance of the traditional birth attendants is maintained by the generallyaccepted norm in the communities according to which a considerable number of women chose to deliver their babies at home. The partnership with Village Health workers and traditional birth attendants is valued highly as one of the greatest strengths of Lesotho's heathcare delivery system, and because of its support for health programs in the villages. Evidence shows that "success 
in the continued training of Village Health Workers and Traditional Birth Attendants heavily supported by UNICEF has contributed to increased immunization coverage" (Ministry of information, Lesotho, 1996:152).

During the course of implementing The Expanded Program on Immunization in Lesotho, it is expected that the roles of the state and non-state actors should be defined in such a manner that every role player is properly equipped with the necessary terms of reference to enable them contribute towards the functioning of the whole system. Based on the above, the main assumption of this study is that state and non-state actors are supposed to work both as individual entities and in cooperation in order to deliver quality and sustainable health care across the Kingdom of Lesotho. Specifically on the government side, the responsible government agency is the Ministry of Health and Social Welfare, which:

- Ensures the consistent availability of vaccines at all times. The ministry's EPI Review report of July 2001 revealed that almost 1 in 10 facilities experienced stock shortages in May 2001;

- Initiates strategies of enforcing the 'supermarket approach' by all the Health Service Areas. This approach ensures uninterrupted access to vaccines at all times, including weekends, in order to reduce missed opportunities. The 2001 EPI review report (as previously mentioned) indicated that $81 \%$ of facilities still immunize only on a specific day of the week and many facilities refuse to vaccinate children if their mothers bring them on the "wrong date, day or time." ;

- Should enforce and motivate timely and complete reporting by various Health Service Areas;

- Should ensure the equitable distribution of antigens and also focus on supplying the antigens that are lacking, especially in the rural areas;

- Should create and publicize clear policy statements about the support, monitoring and evaluation of private practitioners' immunization activities; and,

- Should coordinate the activities and functions of all role-players

In order to realize its objectives, the Ministry of Health and Social Welfare is working in partnership with international organizations to provide immunization services. Different donors and partners play different roles in the implementation of EPI. The amounts contributed vary depending on the amounts spent in the previous years. Table 2 lists the partner organizations and the roles they play in immunization in Lesotho. 
Table 2. Partner Organizations and their Roles in Immunization

\begin{tabular}{|l|l|}
\hline Name of Organization & Services provided in Immunization \\
\hline UNICEF & Procurement of vaccines and logistics \\
\hline WHO & Assists with technical experts and funds \\
\hline IRISHAID (DCI) & Funding \\
\hline GLOBAL GAVI & Funding and supplies Hepatitis B vaccine \\
\hline JAICA & $\begin{array}{l}\text { Procurement of cold chain equipment, cooler boxes and freezers } \\
\text { Provides funding for vaccines } \\
\text { In the process of supporting 5 year plan for EPI }\end{array}$ \\
\hline ROTARI International & Polio Eradication \\
\hline
\end{tabular}

Ministry of Health and Social Welfare (2002)

According to the Lesotho News Agency (LENA), in July 2004 Japan donated immunization and vaccination equipment to the EPI unit of the Ministry of Health and Social Welfare in the form of cold chain equipment and polio and measles vaccines. In his remarks, the Minister of Health and Social Welfare indicated that the Government of Lesotho is committed to the well-being of the Basotho children who are the future of the country. He alluded to the fact that the Government of Lesotho has made the good health and education of children its top priorities (LENA, July 2004).

In its strategic plans, UNICEF is guided by the principles of the Convention on the Rights of the Child (CRC) and the Convention on the Elimination of All forms of Discrimination against Women (CEDAW). During 2002-2005, their focus was on HIV/AIDS as one of the five priority areas of action where the potential for change and impact on children's lives is considered to be the greatest. The other four priorities were girls' education, early childhood immunization, strengthening health systems, and protecting children from violence, abuse, exploitation and discrimination. Non-Governmental Organizations (NGOs) in Lesotho also collaborate with the Ministry of Health and Social Welfare to provide health services. The Christian Health Association of Lesotho, Lesotho Highland Development Authority, the Red Cross, Maseru City Council and others have actively been involved specifically in the immunization project. These organizations are mainly making their contributions in the domain of information, education and communication. While some of the NGOs are members of the ICC (InterAgency Coordinating Committee) various agencies and partners that are supporting immunization services are coordinated and organized through an ICC mechanism. 


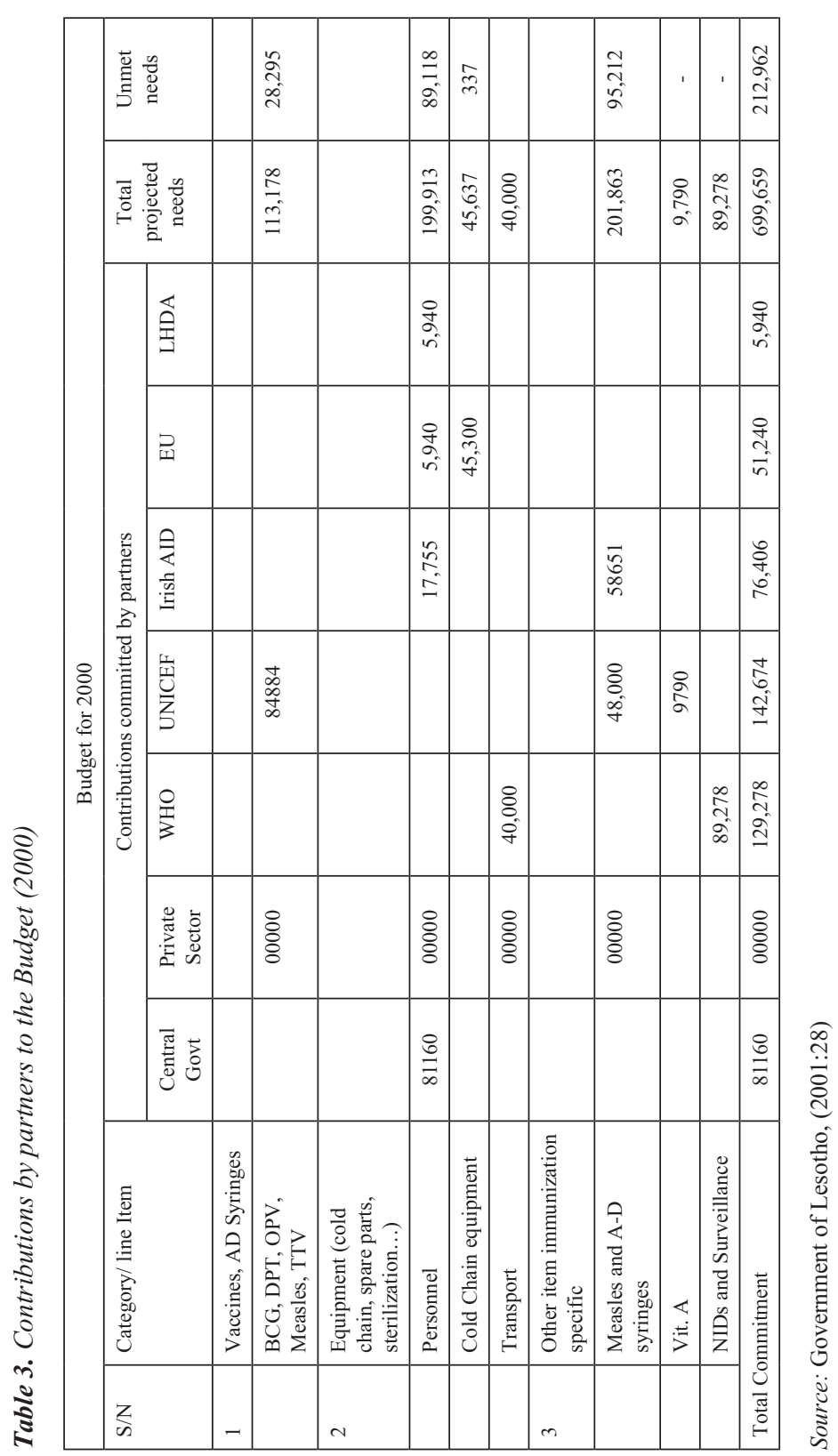




\section{Budget Allocations and Funding}

In all the years since the inception of EPI, the Government of Lesotho has provided the needed funding through annually-approved budget allocations. According to the interviews, due to expenditure that was below the budgeted amounts, the balances have always reverted to the government. Evidence shows that of the amount allocated to the Health Sector by the GOL, 15\% was made available for the procurement of vaccines (Government of Lesotho, 2001) and this trend is liable to continue. In their application for funding from the Global Alliance for Vaccine and Immunization (GAVI) and the Vaccine Fund, the Government of Lesotho requested support for strengthening immunization services, injection safety and support for new vaccines. Table 3 shows the level of financial and other material support and contributions by relevant stakeholders and donor agencies towards the implementation of the Expanded Program on immunization in Lesotho. The table further reveals the extent to which donor or partner agencies contribute to the Lesotho immunization project. It is glaringly obvious that international non-state agencies made more financial and material contributions to the program than the Government of Lesotho.

\section{Development of Framework Documents}

The government of Lesotho was responsible for the articulation of Lesotho's Vision 2020, which is a longer-term document, and the Poverty Reduction Strategy Paper (PRSP) which sets the frame for a multi-sectoral action program for combating poverty in the medium-term which is expected to harmonize development partners' contributions. These partners include the EU, the IRISHAID Development Cooperation Ireland (DCI), the German Technical Cooperation (GTZ), the World Bank, the African Development Bank and United Nations agencies. In addition to these, Lesotho is a signatory to the Millennium Development Goals (MDGs). The PRSP has identified eight priority areas, of which health is one. From a donor perspective, PRSP offers the opportunity to properly coordinate all donor assistance for the first time (Development Cooperation Ireland, I2005: 14). The current donors within the Health Sector are the IRISHAID Development Cooperation Ireland (DCI), the World Bank, the Africa Development Bank, the World Health Organization and UNICEF. The IRISHAID Development Cooperation Ireland is considered to be the main donor since it contributes a larger percentage to the sector, having pledged to assist the Government of Lesotho to meet its Millennium 
Development Goals. For instance, the key components of DCI's support to the Health Sector during its 2005-2007 strategic plans include:

- Building capacity to support decentralized service delivery;

- Strengthening the Health Sector response to HIV/AIDS, including creating a system of care and support that involves civil society organizations;

- Building the capacity of CHAL and its institutions through the training and renovation of selected health centers;

- Supporting the development of a formal partnership between the Ministry of Health and Social Welfare and the Christian Health Association of Lesotho;

- Strengthening planning, financial and information management systems (especially of sex disaggregated data, including a demographic health survey);

- Supporting the development of a strategy to meet human resource needs in health; and,

- Participating in joint planning and reviews with other donors to agree on a joint framework for cooperation.

\section{Coordinating Partnership Functions}

The Ministry of Health and Social Welfare, the relevant organ of Lesotho's government, is working in partnership with the international organizations who play different roles in the provision of immunization services. The coordination of such activities has become imperative in order to sustain the delivery of the services. As an important role player, the Government of Lesotho aims to improve immunization and the availability of safe vaccines and provisioning through a coordinated relationship with international organizations and other civil society groups in Lesotho. For this purpose, a high-powered multi-stakeholder coordinating committee known as the InterAgency Coordinating Committee was instituted so that it could oversee the acquisition and implementation of The Expanded Program on Immunization in Lesotho. Since its institutionalization, this committee has been working realistically on its mandate and continues to meet and discuss The Expanded Program on Immunization issues to date. The current committee was constituted in 1996 and contains several subcommittees that include technical and the social mobilization committees. The summary functions of the Inter Agency Coordinating Committee include coordination, advocacy, program implementation, social mobilization, accountability, and information, education and communication (Fig 3). From an analysis of contributions, 
there is sufficient evidence to suggest that there are specific roles being performed exclusively by individual role-players, especially the relevant government agencies in the partnership. For instance, the provision of human resources and the coordinating function depend solely on the government of Lesotho, while other functions and contributions are non-exclusive (different state agencies and non-state actors perform the functions or provide the required services through collaborative efforts). These include, funding, human resource training, the contribution of materials and equipment and the provision of storage and distributive logistics for the implementation of the EPI in Lesotho which have largely been effected on a collaborative or multiagency contributory basis.

Figure 3. Composition of Interagency coordinating committee

\begin{tabular}{|ll|}
\hline Function & Title/Member Organization \\
a. Chair & Minister of Health and Social Welfare \\
b. Secretary & National EPI Program Manager \\
c. Members & Director General of Health Services \\
& WHO Representative \\
& UNICEF Representative \\
& Chairperson, Rotary International \\
& Health Program Advisor, Ireland AID \\
& Epidemiologist, MOHSW \\
& Head, PHC Services, CHAL \\
& Director, Maseru City Council \\
& Head Laboratory Services \\
& Pediatrician, parastatal \\
\hline
\end{tabular}

Source: Government of Lesotho, (2001), Proposal for Support submitted to the Global Alliance for Vaccines and Immunization (GAVI) and the Vaccine Fund.

\section{THE RELATIONSHIP BETWEEN STATE AND NON-STATE AGENCIES IN SERVICE: COOPERATION, CONFLICT AND CHALLENGES}

The relationship between state and international agencies in implementing the Expanded Program on Immunization is driven by the principles of new world order. The components and major driving forces of the new world order include democratic governance, accountability, responsiveness in governance and trade liberalization. Thus, the relationship between international agencies and the government of Lesotho concerning EPI administration from the 
1990s to 2004 clearly shows the new world order at work, where an analysis of distribution (based on the coverage of antigens) indicates tremendous coverage (Figure 4). Immunization coverage varies slightly for all antigens during the years under study with a noticeable decrease from 2003 to 2004. It should be noted, however, that the data for 2005 refers to the first quarter only.

Figure 4. The Expanded Program on Immunization coverage per antigen 1995-2005

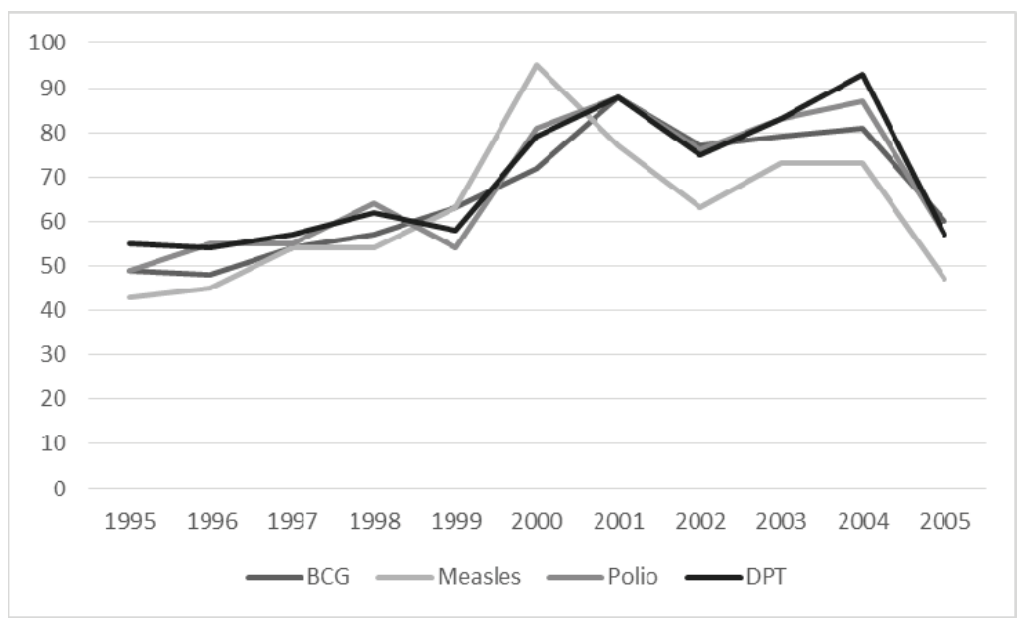

Source: Obioha et al, 2006

In line with the global targets set at the World Health Assembly in 1988, the Lesotho EPI was committed to increasing its vaccination coverage and also aimed to eradicate Poliomyelitis so that by 2005 Lesotho would be certified as polio free. According to Lesotho EPI reports for 1995-2005, no confirmed cases of polio were found in the country. Further examination of the average change in the growth of antigens, from 1995-2005 shows (Table 4) that polio coverage changed the most (average of 3.7\%), while DPT changed least (average of 2.2\%). For all the antigens Lesotho experienced the highest increase in $2000(37.3 \%)$, while a drastic drop relative to the previous year was experienced in $2005(-33.8 \%)$. 
Table 4. Annual Growth Rate for all Antigens Immunized

\begin{tabular}{|c|c|c|c|c|c|c|c|c|c|c|c|c|}
\hline \multicolumn{10}{|c|}{ Immunization Trend Lesotho 1995-2005 } \\
\hline Antigens & 1995 & 1996 & 1997 & 1998 & 1999 & 2000 & 2001 & 2002 & 2003 & 2004 & 2005 \\
\hline BCG & 49 & 48 & 54 & 57 & 63 & 72 & 88 & 77 & 79 & 81 & 60 \\
\hline Measles & 43 & 45 & 54 & 54 & 63 & 95 & 77 & 63 & 73 & 73 & 47 \\
\hline Polio & 49 & 55 & 55 & 64 & 54 & 81 & 88 & 76 & 83 & 87 & 57 \\
\hline DPT & 55 & 54 & 57 & 62 & 58 & 79 & 88 & 75 & 83 & 93 & 57 \\
\hline Average & 49 & 50.5 & 55 & 59.2 & 59.5 & 81.7 & 85.2 & 72.7 & 79.5 & 83.5 & 55.2 \\
\hline
\end{tabular}

\begin{tabular}{|c|c|c|c|c|c|c|c|c|c|c|c|}
\hline \multicolumn{2}{|l|}{ Lesotho \% Change 1996-2005 } \\
\hline Antigens & 1996 & 1997 & 1998 & 1999 & 2000 & 2001 & 2002 & 2003 & 2004 & 2005 & $\begin{array}{c}\text { Ave. } \\
\text { Years }\end{array}$ \\
\hline BCG & -2.0 & 12.5 & 5.5 & 10.5 & 14.2 & 22.2 & -12.5 & 2.5 & 2.5 & -25.9 & 2.9 \\
\hline Measles & 4.6 & 20 & 0 & 16.6 & 50.7 & -18.9 & -18.2 & 15.8 & 0 & -35.6 & 3.5 \\
\hline Polio & 12.2 & 0 & 16.3 & -15.6 & 50.0 & 8.6 & -13.6 & 9.2 & 4.8 & -34.4 & 3.7 \\
\hline DPT & -1.8 & 5.5 & 8.7 & -6.4 & 36.2 & 11.3 & -14.8 & 10.6 & 12.0 & -38.7 & 2.2 \\
\hline Average & 3.0 & 8.9 & 7.7 & 0.4 & 37.3 & 4.2 & -14.7 & 9.2 & 5.0 & -33.8 & 2.7 \\
\hline
\end{tabular}

Source: Obioha et al, 2006

Indeed, a good relationship has been developed between the government and other NGOs and memorandums have been developed for some of the NGOs (e.g. the Blue Cross and the Red Cross). However, with the rest of the NGOs there is no binding agreement and this tends to aggravate the problem of lack of communication. The absence of clear mechanisms of communication have made it difficult for a straightforward relationship to exist, particularly with regards to the support that the government is expected to give to the Christian Association of Lesotho (CHAL). In April 1999 the WHO initiated a Lesotho Country Study of NGO Profiles for all the NGOs participating in the Health Sector. This was a step towards creating a tripartite collaboration between government, CHAL and NGOs (Ministry of Health and Social Welfare, 2000: 41). It implies that all the NGOs that are involved in the implementation of The Expanded Program on Immunization in Lesotho do not unambiguously enjoy an equal level of recognition by, and collaboration with the state. What has importantly been maintained is the good working relationship between various role-players in the service, irrespective of the level of recognition by the state. This has to a large extent led to the smooth implementation of the program in the country, which takes its cue from the accomplishments of other countries that are the results of collaborative efforts between host countries and partners 
in the fight against Polio. The above facts suggest that the Polio Eradication Initiative (PEI) has brought into EPI, a management system and a complex amalgamation of interests and ideas concerning EPI implementation. Recent report implicitly reveals how vigorous and coordinated implementation of EPI in Lesotho through the years have yielded positive dividends in terms of onset and outbreak of child killer diseases in Lesotho. None of the EPI target diseases except measles was reported as one of the top ten causes of children admissions into hospitals, although it constituted mere 8.5 percent of the total cases (Bureau of Statistics, 2014: 10). This result has two implications in understanding the current situation and outcome of immunization in Lesotho. While it substantiates the success and gains in immunization, it also indicates that the implementation of immunization is not yet a total success, especially in the case of measles. The results from the implementation of the EPI in Lesotho are a function of cooperation amongst and between role-players and stakeholders.

On the opposing side, conflict situations and challenges are unavoidable in every cooperative effort and relationship. There are areas of conflict between state and non-state role-payers which include communication and coordination functions. Critical analysis of the scenario suggests that communication between the central ministries and agencies responsible for implementing the program is not systematic and does not ensure timely follow-up or effective consultations, as is required or as would be necessary for a meaningful partnership to exist. Reporting has also been deemed somewhat ineffective. This is due to absence of a no unified monitoring system, hence different donor agencies that are active in the sector use different reporting formats for similar activities. This requires the duplication of efforts and heaps demand on the already weak and inadequate capacity for coordination (Ministry of Health and Social Welfare, 2000: 40).

Donor coordination is designated to be the responsibility of the Ministry of Planning. However, there is robust evidence of laxity and poor coordination among donor agencies, the Ministry of Planning and Ministry of Health and Social Welfare. Interestingly, though largely unexplained, donor agencies such as UNICEF, EU and IRISHAID (among others) have overlooked the newly-developed Health Planning Unit of the Ministry of Health and Social Welfare and have continued to carry on their activities with other departments of interest, which has made the monitoring of activities of all the role players by the responsible ministry very difficult (Ministry of Health and Social Welfare, 2000: 41). Experience has shown that one of the obvious and unpalatable outcomes of this may be that the external funding agencies, who are supposed to be monitored by local agencies, dictate the pace of operations in the 
immunization process. By this act of bypassing the authorized monitoring and coordinating agency of the government (Ministry of Health and Social Welfare), the international partners are in violation of the protocols: this implies a conflict of interest. There are a series of unsubstantiated claims and suspicion from the Government of Lesotho about what might be the ulterior motive of the violating partners. It is therefore evident that unequal power relations exist at the level where donors and international partners make major decisions regarding The Expanded Program on Immunization to the extent that the program is becoming more externally-driven and hence susceptible to the will of donors and partners. The erosion of local autonomy in this regard has manifested in a lack of trust towards locally-generated outputs and resources. For instance, on some occasions international agencies have not relied on the statistics provided by competent local agencies in the country as authentic figures. These challenges are imminent and may lead to tasks remaining unaccomplished in the Expanded Program on Immunization in the country.

There is also a general weakness as regards the lopsided attention paid to urban locations, with less attention being paid to rural areas which has led to the uneven distribution of positive outcomes of the project. The effect of the unequal distribution of clinical staff is to a large extent correlated with dichotomous immunization outcomes in favor of urban locations (Figure 5).

Figure 5. Rural-Urban Distribution of Immunization Coverage 2002

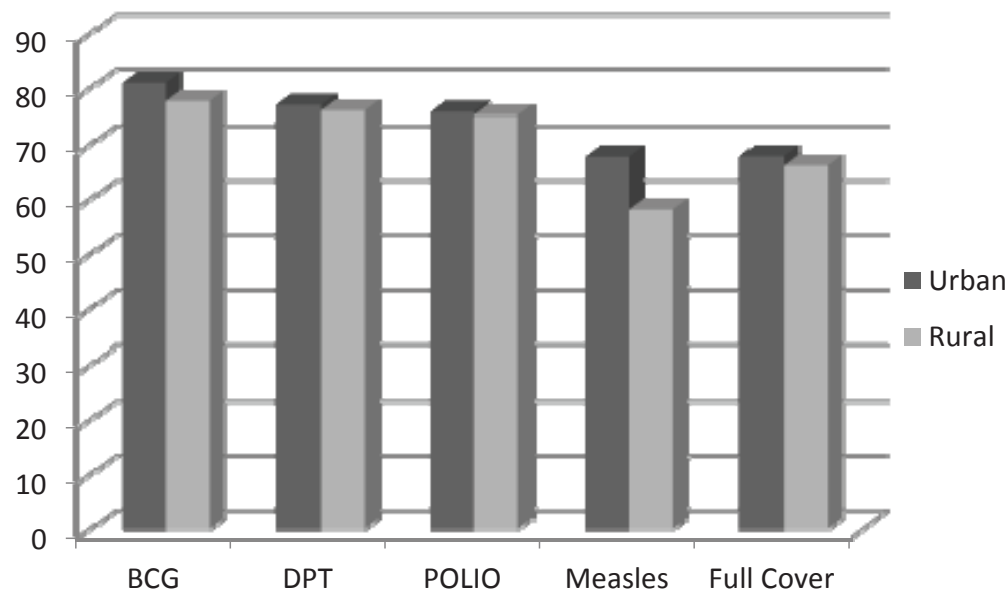

Source: Obioha et al, 2006 
For instance, data for 2002 indicate a slightly higher coverage of urban areas compared to rural, both for specific antigens and full coverage. Besides a shortage of clinical staff, this may also be attributed to the remonetess of some areas in rural mountains that are hard to reach and where reporting may be delayed or relatively poor compared to urban areas that are easy to reach, monitor and evaluate.

\section{CONCLUSION}

This study about the structure of health care delivery and implementation of the Expanded Program on Immunization in Lesotho showed that Lesotho's primary health care system is grassroots oriented in implementation, with an effective and functioning community health worker system which is fully utilized in conjunction with voluntary health workers. Various policies emanating from the Lesotho government support the implementation and coordination of the program in the country. The smooth implementation of the program is facilitated by the designation of functions amongst local (Lesotho Government and agencies) and international partners. Even though there is close collaboration between state role players and some local non-governmental organizations, there is a strong indication that the implementation of the EPI program is being slowed down by the duplication of functions among role-players which results from the poor coordination of the activities of participating agencies and sometimes the willful and deliberate attempts of some international partners to undermine the authority of the state monitoring agency.

\section{REFERENCES}

Bureau of Statistics (2014), Health Statistics Report 2010. Maseru, Bureau of Statistics. Statistical Report No 25. http://www.bos.gov.ls/Downloads.htm

Government of Lesotho (GOL) (2001), Proposal for Support submitted to the Global Alliance for Vaccines and Immunization (GAVI) and the Vaccine Fund. Maseru, Government of Lesotho.

Irish Aid (2005), Development Co-operation Report 2005. Ireland, IRISH AID Development Cooperation Ireland.

Ministry of Health \& Social Welfare (MOHSW) (2002), Guidelines for Lesotho The Expanded Program on immunization [LEPI]: Policy Implementation. Maseru: Lesotho The Expanded Program on Immunization.

Ministry of Health \& Social Welfare (MOHSW) (2002), 'Health Facility List'. 
Maseru, Lesotho MOHSW.

Ministry of Health \& Social Welfare (MOHSW) (2002), 'EPI Revised Policy (Draft)'. Lesotho The Expanded Program on Immunization. Maseru, Lesotho MOHSW.

Ministry of Health \& Social Welfare (MOHSW) (2001), Report of a review of the Expanded Program on immunization in the Kingdom of Lesotho. Maseru, Lesotho: MOHSW.

Ministry of Health \& Social Welfare (MOHSW) (2000), Lesotho Health Sector Reforms Plan. Maseru, Ministry of Health and Social Welfare.

Obioha E.E., Matobo, T.A. and Ajala, A.S. (2006), The Influence of Socio- Political Environment on Primary Health Care Delivery Patterns in Contemporary Sub-Saharan Africa: The Expanded Programme on Immunization in Lesotho. A Comparative Research Network (CRN) Report submitted to Council for Development of Social Science Research in Africa (CODESRIA), Dakar, Senegal. PriceWaterHouseCooper, UNICEF, GAVI and European Union, (2004), 'Final report on 2003 data Quality Audit Kingdom of Lesotho'. http://www.vaccinealliance.org/ resources/DQA-2004-Lesotho-htm.retrieved 18/01/2005 at $8.00 \mathrm{pm}$.

South African Political Economy Series Trust (2001), SADC Country Studies: Lesotho 2001. Harare: South African Political Economy Series Books.

UNICEF (2003), 'Fighting HIV/AIDS: UNICEF Strategies for Success 2002-2005'. New York: UNICEF.

UNICEF and World Health Organization, (2005), Review of National Immunization Coverage 1980-2004: Maseru: UNICEF, Pp1-10.

Wittet, S and Aston, R (2000), Realizing the Full Potential of Childhood Immunization: How Health Professionals Can Make a Difference. Washington, Bill and Melinda Gates Children's Vaccine Program PATH. Occasional Paper No 1. http://www. path.org/vaccineresources/files/CVP_Occ_Paper1.pdf

World Health Organization (2000), Polio News, Geneva: WHO. Issue 7, March 2000. 